\title{
1984 CALGARY AREA BLUEBIRD TRAIL RESULTS
}

D.J. STILES, 20 Lake Wapta Rise SE, Calgary, Alberta. T2J 2M9.

Following are the results of the sixth year of monitoring of Calgary area bluebird trails by members of the Calgary Field Naturalists' Society. Calgary area bluebird trails were increased this year to 939 boxes on 582 miles of line, and fledged approximately 1900 Mountain Bluebirds and 2300 Tree Swallows.

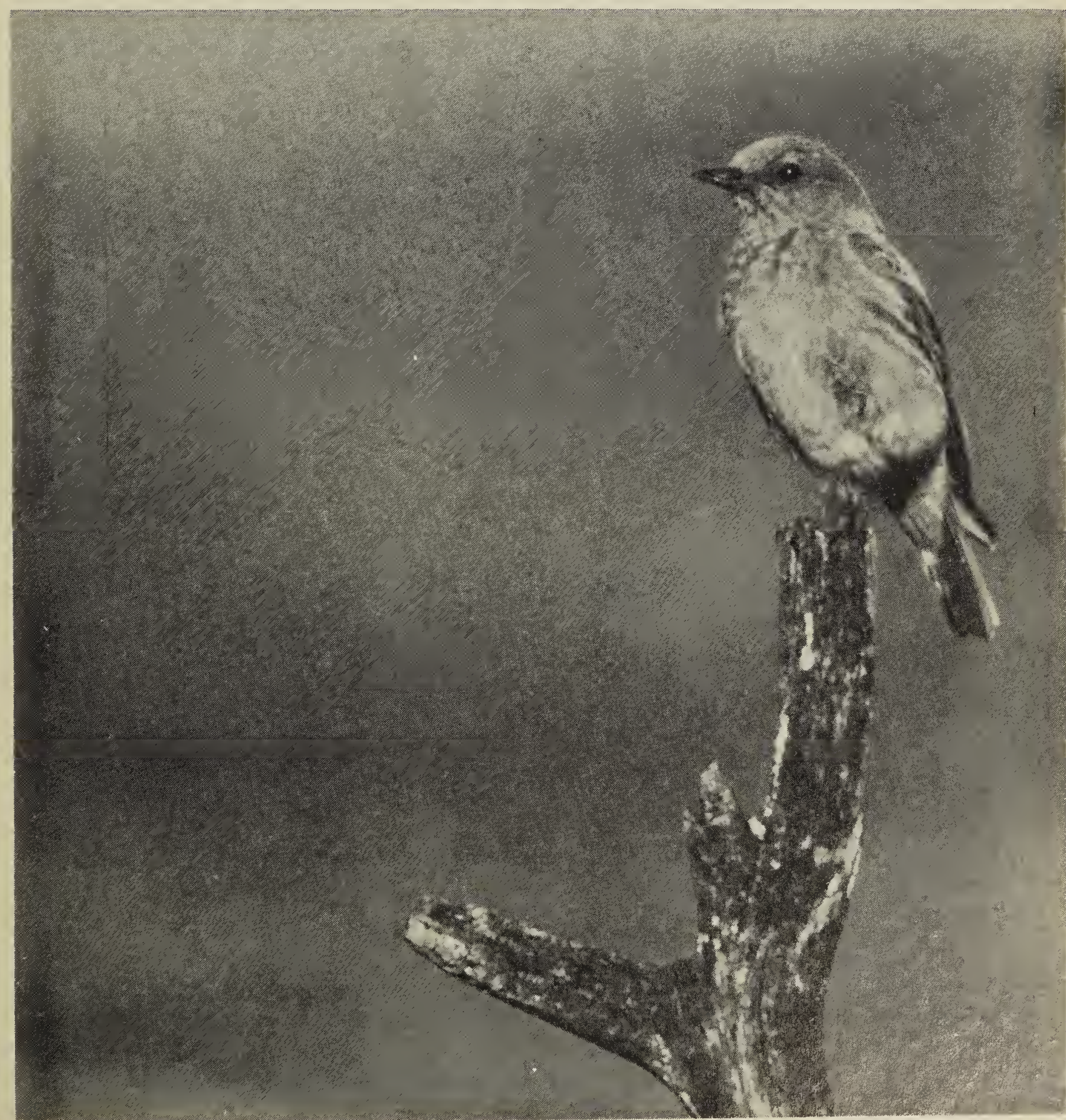




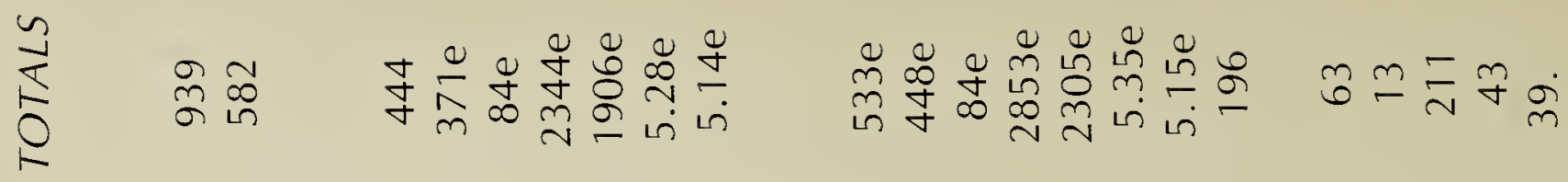

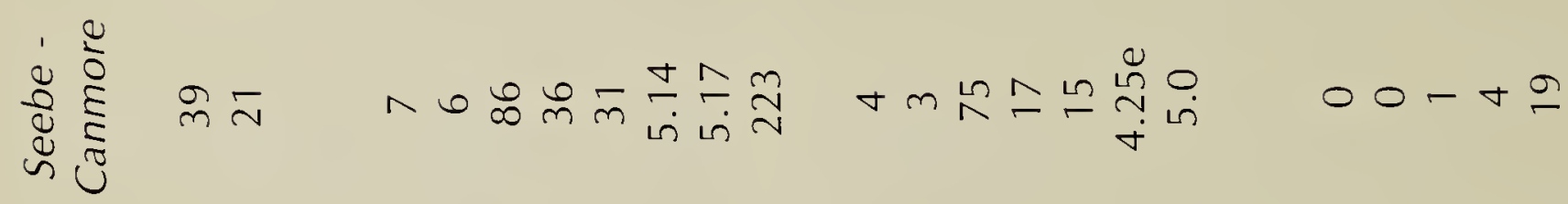

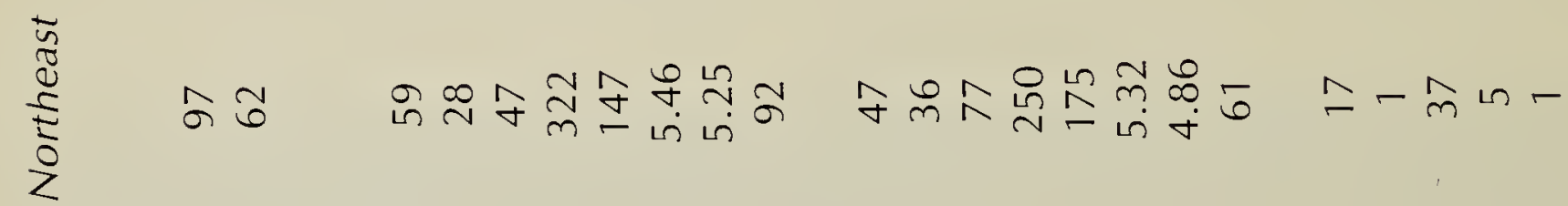

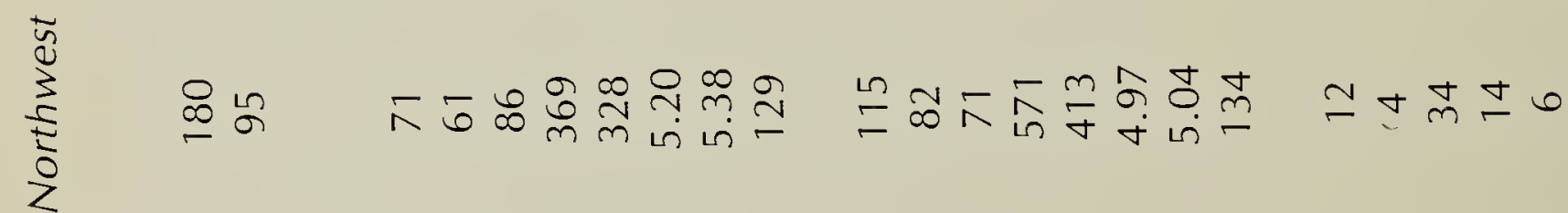

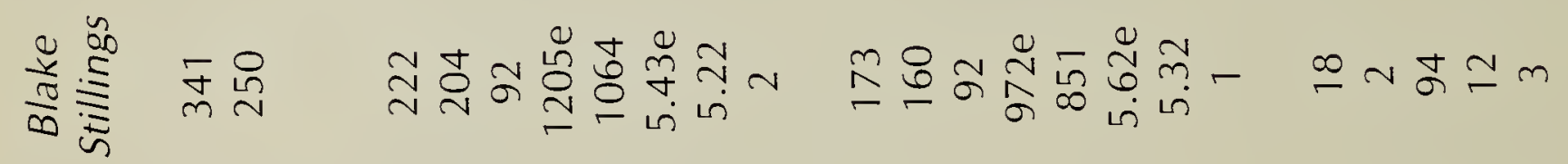

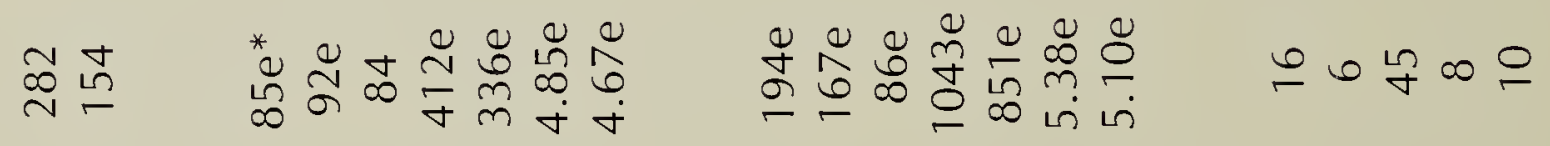

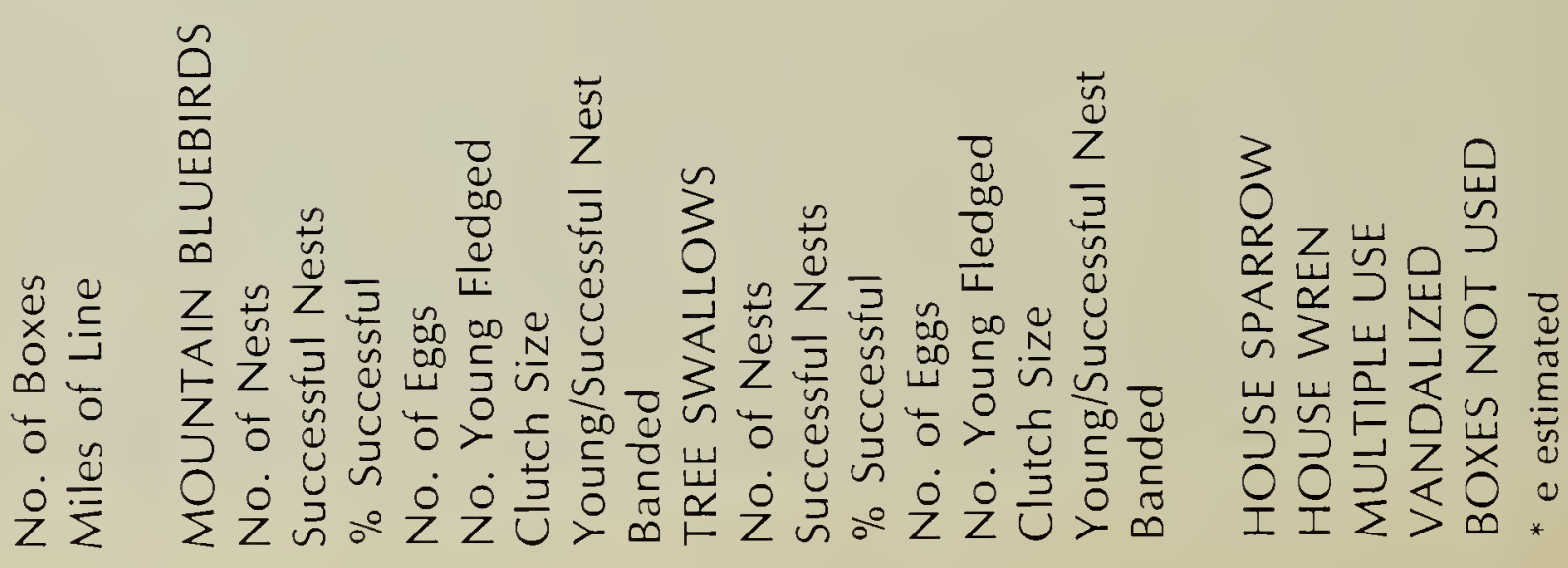


For bluebirds 1984 was a banner year, primarily due to an early spring and an unseasonably warm month of May. This allowed an early start of nesting and a dramatic increase over 1983 in bluebirds from 214 first broods to 328 - a $53 \%$ increase!

Part of the increase was accounted for by members increasing the number of boxes by $15 \%$. But Tree Swallows showed only a modest increase of $10 \%$ (less than the increase in box numbers). On several of the trails the clutch size for Tree Swallows was less than that of bluebirds (i.e. Elkton 5.47:5.61 and East Didsbury 5.32:5.46 for Tree Swallow:bluebird). Normally Tree Swallows have slightly larger clutch sizes as determined by Pinel between 1973 and 1978, with Tree Swallows at 5.71 and bluebird clutches averaging 5.26.

\section{Project Nestbox Alberta}

The year was significant for the start of Project Nestbox Alberta, which is a federally funded summer project. Seven students were hired to cover the province, listing data on nestbox dimensions, habitat and occupancy. Calgary area's student was Eileen Dyck, who faithfully contacted each monitor and accompanied them on their trails acquiring the needed information. We all enjoyed working with Eileen and look forward to the results which will tell us such things as which nestbox type and hole size has highest bluebird occupancy.

\section{New Breeding Species}

Two pairs of Western Bluebirds were reported in the foothills, 1 and a pair of Violet-green Swallows were reported by Kay Morck to be nesting at a farm near Springbank (in press).

\section{Missing Eggs and Young}

First time monitors wanted to know why sometimes fewer eggs were present at subsequent monitorings, or fewer young hatched than there were eggs, with no ad- ditional eggs in the nest. Bryan Shantz of Ellis Bird Farm had the following answers:

Occasionally miscounting occurs, but not enough to account for most cases. Infertile eggs, although sometimes still found present after fledging, may also be removed by the adult birds. Predation by House Sparrows or House Wrens is possible. Human intervention is also possible, but is expected to be rare.

Probably the most likely explanation is the predation. Sparrows or wrens will peck the eggs, and the bluebirds will remove broken shells. Similarly, if infertile eggs are broken the adult usually removes the shells.

\section{Observations}

\section{Bluebirds}

A clutch of 8 bluebird eggs hatched and fledged successfully. One bluebird nest included string in its construction. A single fledgling entangled its foot in this string, and in its desperate attempts to leave the nest had broken the leg right off, however it still remained held by its upper leg. When freed, it flew off - no doubt to an early fate.

In a case of vandalism someone shot between the 6 and 4 on box 64 but missed the bluebird; she must not have been on the nest at the time.

On one section of trail 52 out of 56 boxes contained bluebird nests. Of these 45 were successful. It was not immediately obvious why that loop of the trail should have so many more bluebirds than adjacent loops, since the habitat looks much the same. One box in this group hatched six young, which had all died with the perfect half shells still in the box. Blake Stillings, the monitor, stated "I think the hen bird was killed just before the eggs hatched and heat from embryo and sun completed the hatch, then young died and egg shells were never removed. 
One nest contained two young bluebirds estimated to be about 4 and 8 days old. It appeared that one egg from a first clutch and one from a later clutch also hatched. Both of these birds fledged.

\section{Tree Swallows}

For the first time in two years there was a report of a double brood of Tree Swallows, with 10 young fledging from one nest. In each of three nest boxes two broods of swallows were raised. Although rare in Alberta, this does happen occasionally if the first brood is started early. In one nest box a brood of Tree Swallows followed two broods of bluebirds.

In a situation similar to the bluebird nest with the string, an adult Tree. Swallow was caught in plastic filament, became tangled, and died.

Two trails had Tree Swallows only and no bluebirds. Again there were reports of dead broods of Tree Swallows which were at least half grown. In some instances there was evidence of disease, with the young incompletely feathered, but not always. Fortunately, there were only 2 or 3 such cases per trail.

\section{Other Species}

Chickadee nests were again reported, with two nests each of Black-capped and Mountain chickadees. One of the Blackcapped Chickadee nests was on a trail where they had not nested before, but it was not successful.
House Sparrows continue to plague one monitor. Although seven House Sparrow prone boxes were removed last year, there were ten boxes with first time House Sparrow nests in them this year. This trail is 6-8 years old and most of the houses are over $0.5 \mathrm{mi}$. from buildings.

\section{Paired Boxes}

An experiment in 1984 was the extensive use of paired boxes. The biological theory for paired boxes is that a nesting species will tolerate another species nearby, but not another pair of its own kind. With paired boxes it was believed the Tree Swallows would use the second box and not drive out the bluebirds, as they frequently do when they arrive after the bluebirds have already begun nesting. The results of the paired box trials are given in Table 2 . The distance between paired boxes varied from 3 to $25 \mathrm{~m}$, with the most common spacing between 10 and $15 \mathrm{~m}$. At present the distance apart does not seem to matter and further experimentation would be needed to determine if it is critical.

One monitor paired all 31 boxes on the trail. While this did result in 9 cases where bluebirds and Tree Swallows used adjacent boxes, 22 other pairs had one box vacant. Of the nine pairs where both boxes were used the Mountain Bluebirds used the old flat-topped boxes in seven and the new slant-roofed boxes in only two cases. Since the bluebirds arrive about a month earlier, they have first choice of boxes.

Table 2. RESULTS OF USING PAIRED NEST BOXES

\begin{tabular}{|c|c|}
\hline Pairing & $\begin{array}{l}\text { Bluebird + } \\
\text { Swallow }\end{array}$ \\
\hline
\end{tabular}

All boxes on line 922 


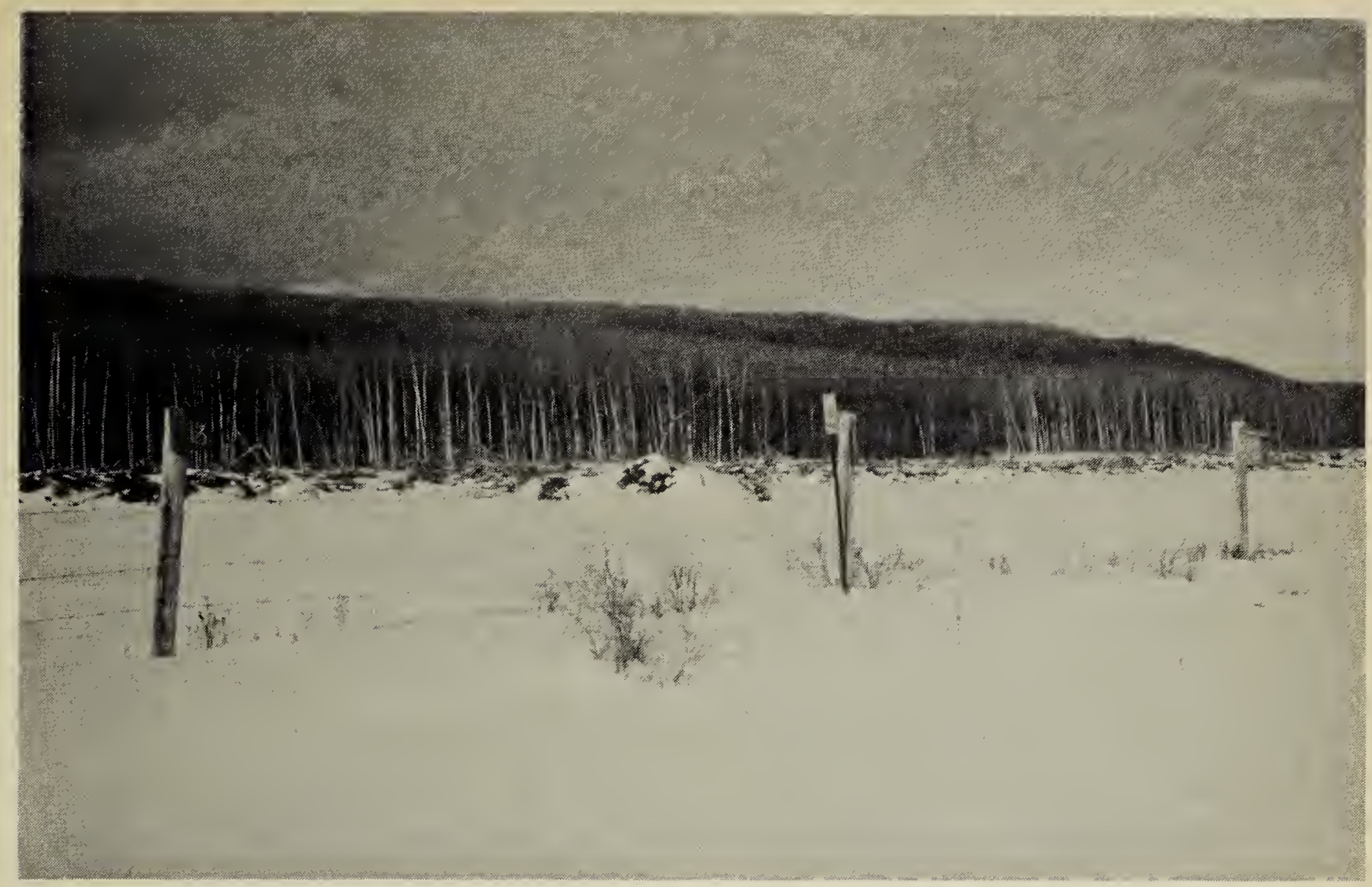

Paired boxes show two styles. This pair was used by Mountain Bluebirds and Tree Swallows.

Two monitors carried extra boxes with them when monitoring. When a pair of Tree Swallows appeared in the vicinity of an active Bluebird nest, a second box was set up 10-15 $\mathrm{m}$ from the existing box. The system was successful, with the Tree Swallows using six out of the seven pairs created.

Other monitors had seven pairs of boxes in place at the beginning of the season. Four of these attracted both bluebirds and swallows, two pairs had one box vacant and the remaining pair had both boxes used by swallows. In this latter case both houses were at the edge of Aspen Poplar woods.

In two cases the bluebirds and swallows "switched" houses from where they originally started to nest.

In general the paired boxes appear to have a high success ratio, particularly where competition between bluebirds and swallows is known to occur, or suspected. Calgary area monitors will be putting up more paired boxes in coming seasons.

\section{Banding in 1984}

Ray Woods and Don Stiles both banded in 1984. The results are presented in Table 3. Recaptures and returns are noted in Table 4. Recaptures are mostly birds banded as adults.

The 1984 Mountain Bluebird recaptures were females recaptured in the same nest with a second brood. Of the eight adults banded in previous years, six were found in the same house and the other two within a mile of the original banding site. The single young recaptured was 2 miles from the nest site. 
Species

Mountain Bluebird

Tree Swallow

Five of the 15 adult Tree Swallows recaptured were in the same house, 7 were within $2.5 \mathrm{mi}$. and the remaining 3 within $6 \mathrm{mi}$. The three young recaptured were found $1.5,8.5$ and $10.5 \mathrm{mi}$. from the banding site. This suggests that young are much more wide ranging in their search for nest sites than are the adults. Two adult Tree Swallows have been recaptured twice. Both were banded as adults (in 1981 and 1982), and both were recaptured in the same nest box in which they had been banded in 1983 and 1984.

The band returns from Mountain Bluebirds were both from adult males. both
Adults

Young

Total

36

187

223

60

136

196

banded as young in 1983. One died 25 June when it flew into a patio window 0.5 miles from where it was banded. The other was found dead in a horse trailer near Okotoks 7 September 1984. It was banded and color banded by Bryan Shantz northeast of Red Deer. It had raised a brood in 1984, and the female had raised a second brood.

The single Tree Swallow return was from a young banded in 1981, $7 \mathrm{mi}$. east and 2 mi. north of Didsbury, Alberta. It died in a bird house in 1983 at Diamond City, Alberta about $5 \mathrm{mi}$. north of Lethbridge (probably killed by House Sparrows). This is about 130 miles from where the bird was banded as a young.

Table 4. RECAPTURES AND BAND RETURNS 1984

Species/Age when Banded

Year Banded:

Total

$\begin{array}{llll}1981 & 1982 & 1983 & 1984\end{array}$

\section{RECAPTURES}

Mountain Bluebird

Adult

Young

1

7

2

10

1

Tree Swallow

Adult

Young

1

3

11

15

12

3

RETURNS

Mountain Bluebird

Young

Tree Swallow

Young 